\title{
Views from Tibet: NDEs and the Book of the Dead
}

\author{
Carl B. Becker \\ Osaka University Faculty of Letters \\ Osaka, Japan
}

\begin{abstract}
This article presents a Tibetan perspective on near-death experiences (NDEs) and life after death. Tibetans have been concerned with death and deathbed visions from ancient times. After reviewing the beliefs of the Bon religion and of Vajrayana Buddhism, this article focuses on the theories of the Tibetan Bardo Thodol or Book of the Dead (Evans-Wentz, 1957). Many similarities to modern NDE reports are noted, including hearing a noise and moving through darkness into light, out-of-body-type experiences, heavenly and hellish deities and scenery, life-review and judgment, etc. It is seen that the Tibetan Buddhist philosophical idealism, while challenging traditional paradigms, has potential to explain some previously inadequately understood NDE findings such as personal and cultural variations.
\end{abstract}

\section{THE TIBETAN WORLD-VIEW}

Tibet's unique geographical setting has strongly influenced its philosophy and history. Occupying over a million square miles in the middle of the Asian continent, Tibet is severely isolated from its neighbors by the Himalaya and Kunlun mountain ranges. Although its snows feed the Mekong, Brahmaputra, Indus, Yang-tse, and other major rivers, the mountains block the monsoons from the south, so annual rainfall is extremely low. Therefore the Tibetans can raise few crops, and must depend largely on nomadic sheep- and yak-herding for their livelihoods. Tibet's barren plateaux range from 11,000 to 18,000 feet in altitude, where oxygen is too thin for the unacclimated visitor. Because of the extreme altitude, the daily sun is very strong, but temperatures at night plunge to freezing even in summer. The winter adds to sub-zero temperatures the perils of blizzards, hailstorms, and windstorms carrying abrasive gravel and destructive stones. Thus, the land has never been particularly hospitable, and this environment early gave rise to its inhabitants' beliefs in malevolent

\author{
Anabiosis - The Journal for Near-Death \\ Studies, Spring 1985, Vol. 5, No.1 \\ Copyright (C) 1985 IANDS
}


powers greater than man. More than in other countries, the unusual environmental conditions of Tibet have been a strong influence on the philosophy and world-views of its people (Tucci, 1967, pp. 19-24). The nomadic, meat-eating habits of the Tibetans stand in obvious opposition to the lifestyle of semitropical India. Since fuel is scarce and boiling temperatures are lower at high altitudes, boiling is the chief means of cooking, further robbing the Tibetans' limited diet of needed nutrients. Taken together, a poor diet, severe climate, lack of oxygen, and frequent bouts with plagues early disposed Tibetans to take for granted many hallucinatory and paranormal experiences. This in turn led to their ready acceptance of philosophies that explained and situated such phenomena in a coherent picture of the universe. The first of these systematized philosophies was known as the Bon.

Bon: Pre-Buddhist Tibetan Philosophy and Religion

Like early Chinese philosophies, the Bon religion held that there were twin spirits in man (pho-lha and dGralha), which cooperate to protect and govern him, and which depart at death for other realms (Hoffman, 1961, pp. 17-23). If not properly exorcised and sent off, the disembodied spirits of man were said to haunt his former habitation shortly after death (Ekvall, 1964, p. 39). Malevolent spirits of the air, earth, and water were held to cause sickness and death unless propitiated by human or animal sacrifices (replaced by cffigies after the advent of Buddhism). After death, the souls of virtuous people were thought to ascend to Heaven, while wicked souls were condemned by the lord of demons, rTsiu (Yama), to vividly described hells (Hoffman, 1975, pp. 94-100).

To assist the soul in its postmortem adventures, the corpse was carefully buried with clothes and provisions (a striking contrast to the later Buddhist practices of cremation or dismemberment and exposure!). The Bon believed that shamans could communicate with the spirits of the dead through trance-possession and could visit the world of the dead and return. These ideas persisted, to influence the Tibetan interpretation of Tantric Buddhism when it arrived (NeneskyWojkowitz, 1956, pp. 414-440).

It would be unfair to dismiss Bon as mere animism. From ancient times, the Bon religion accorded a central role to death and funeral ceremonies. Tibetan Buddhism was to continue this theme in a way quite foreign to Indian Buddhism. The un-Buddhist Bon notions that there is an intermediate period during which the soul may return, that 
there is a judgment followed by heavens and hells, and that living men can communicate with the dead, all find their places in Tibetan Buddhism. Guiseppe Tucci claimed that the original ideas of hell came from India, but that the Tibetans supplemented the Indians' visions of "hot hells" with their own "cold hells," founded on their own deathbed experiences:

The Tibetan, with his tendency to the macabre, drew an even grimmer picture of hot and cold hells and frightful tortures which are dwelt on in a hair-raising literature, the delo. This is a series of accounts given by those who, on the brink of death, caught a glimpse of life beyond the tomb, but then returned to tell of the terrifying things they saw. (Tucci, 1967, p. 165)

Within the early Tibetan folk tradition, there are also many accounts of those who died, passed on to judgment and hell, and returned to life to describe their experiences a few days later (Waddell, 1934 , p. 562). Again, there are descriptions of yogic masters who went to the Tusita heavens to commune with their dead masters while in trance (Waddell, 1934, p. 128), and then returned to normal waking life in this world, following the example of Asanga, founder of the yogacara school of Buddhism (Hoffman, 1961, p. 167). There was widespread agreement within Bon and popular Buddhism that prayer services and ceremonies could vicariously assist the progress of departed souls, parallelling the Ulambana (Jap.: O-bon) services in China and Japan (Waddell, 1934, pp. 217, 493). Such facts tend to refute the Christian prejudice that similarities in liturgy and doctrine concerning the afterlife must be borrowings from the Christian tradition; after all, Christianity did not even reach the borders of Tibet until the fifteenth century (Ellam, 1927, pp. 34ff.).

The important point here is that the Tibetans, like the Chinese before them, did not merely adopt Buddhism in its entirety out of political or aesthetic considerations. They accepted Buddhism only insofar as it clarified processes they already knew and illustrated new truths they had not yet verbalized. An oversimplified view might suggest that Buddhism brought the Tibetans their views of heaven, hell, and afterlite. The above evidence documents that such views predated Buddhism and modified it based on the real deathbed experiences of the Tibetan people.

\section{Vajrayana Buddhism}

Buddhism is commonly divided into Hinayana (lesser vehicle) Buddhism of Southeast Asia, and Mahayana (greater vehicle) 
Buddhism of East Asia. The third of the yanas (or "vehicles") of Buddhism, and last in its philosophical and chronological development, was the Vajrayana or Tantrayana. Vajra means diamond, and symbolizes the indestructible, absolute, or void. Tantra means thread or cord, referring to the uninterrupted chain of teachers who supposedly passed these teachings down from generation to generation. In short, the Vajrayana or Tantrayana is an esoteric philosophy bordering on mystery religion. It is passed on orally from master to disciple, and is primarily concerned with self-identification with the absolute. To achieve this understanding of the absolute, it advocates mantras (spells) and mudras (hand gestures) as well as yogic meditation (Hoffman, 1975, pp. 115-125).

Since Vajrayana Buddhism depends on a lineage of teachers and disciples, it has directed more attention to the personalities of its various teachers than to their doctrinal disagreements. Buddhism was first formally introduced to Tibet in the years 747-749 A.D. by Rinpoche (Padma Sambhava), a monk from the Indian university of Nalanda. Buddhism faced repeated opposition from both native Tibetan priesthood and government until the cleventh century, when Atisa, Marpa, and other teachers arrived from India to create vigorous new sects of Tibetanized Buddhism. Meanwhile, previous BonBuddhists "discovered" hidden sutras (texts) on which they based new claims for tradition and superior authority.

Mythologically, Vajrayana Buddhism developed a system of five great Buddhas, lords of the four directions and the center, viz.: Vairocana, Akshobhya, Ratnasambhava, Amoghasiddhi, and Amitabha. These are all taken to be visible manifestations of the ineffable and primordial Adibuddha, the void or absolute. Other buddhas and bodhisattvas, such as Avalokitesvara, Maitreya, and their female counterparts, also are said to exist on this level (Tucci, 1967, pp. 73-78).

The trikaya (three-body) doctrine is central to Vajrayana philosophy. These three bodies point to different levels of reality (Evans-Wentz, 1935, p. 232f.). Ultimately the only reality is Mind, the Absolute, formless Truth and Light, the body of Principle, or dharma-kaya. Buddhas and bodhisattvas possess bodies of spirit and light, which may seem to have form, but are essentially projections of the dharma body. This shape and form of spiritual beings just short of total selfless nirvana is called the sambhogakaya, or spirit body. Finally, there is the material level of the nirmanakaya, the body in which men and animals, mountains and dreams are experienced. 
This nirmanakaya realm, although analogous to the world of philosophical realists, differs from it in two important respects. First, it includes levels of "subtle matter," invisible to our eyes but equally real, in which exist demons, ghosts, titans, and gods. (These four classes, added to men and animals, comprise the six worlds of animate existence in the material world, according to Buddhism). These semidivine beings are unlike bodhisattvas on the sambhogakaya level in that they are still composed of subtle substances and thus still subject to laws of causation, decay, and rebirth. Then the Vajrayana teaching goes one step further: it asserts that all phenomena and experiences are no more than the illusory projections of consciousness; the material level is only a grosser distortion of truth and reality than the spiritual level.

In this view, there is a sense in which any experience is just as real as any other, whether apparently internal and hallucinatory, or ostensibly external and objective. All that is ultimately real and continuous of the individual person is the pure subject, the "mind-store" (alaya-1ijnana)-although that too changes. It is this mind or alayarijianu that cxpericnces, judges, contemplates, and remembers, thus constituting the locus of identity and continuity through the lives of many bodics, or "lifetimes."

This concept has tremendous implications for Vajrayana philosophy. Since all is in mind, then the process of death and rebirth is no longer an inevitable aspect of an external reality to which everyone must submit. It becomes unnecessary to undergo a long succession of lifetimes, for by changing one's conscious thoughts, the whole sequence can be broken or abridged. Even the law of karma is elevated to an entirely different level. No longer do physical actions require inevitable physical effects. Rather, mental acts are all that have any effects at all, whether in apparently external happenings, or in apparently internal visions. Karmic determination of an individual's future good or ill can thus also be avoided or aborted by mental concentration and purification.

To effect this change of consciousness prerequisite to nirvana, mantras, mudras, and samadhi are prescribed. Here too, the Vajrayana departs from the orthodox schools of yoga, in allowing the consumption of meat, wine, and even sexual intercourse with women. At each step, it encourages the realization that none of these phenomena are ultimately real or pleasurable. Under the tutelage of a Vajrayana Lama (guru), the student expects to develop psychic powers (siddhis), to leave his body, and to become able to experience the Absolute in trance. Thus ite can prepare himself for the moment of death, 
when he will direct his consciousness out of his body for the last time, and into final union with Truth, the Dharma, rather than succumbing to any further cycles of rebirth (Evans-Wentz, 1935, pp. $237 f, 254)$.

The vastness of Tibet, the repeated introductions of Buddhism by different Indian monks in different regions, and the varying degrees of assimilation of the old Bon religion into the new Vajrayana Buddhism-all these factors account for the development of numerous schools of Buddhism within Tibet. There are several excellent histories of Tibetan Buddhism that treat these thoroughly (Hoffman, 1961; Waddell, 1932, pp. 10-77; Tucci, 1967, pp. 24-60). More important to us is the fact that all the sects came to use the same Book of the Dead as the central scripture concerning death, dying, and the states immediately following death. More than any other Buddhist text, this book purports to explain the experiences of consciousness after the death of the body, so it is of particular interest to near-death researchers.

\section{TIBETAN BUDDHIST VIEWS OF POSTMORTEM EXPERIENCE}

\section{Origins and Background}

While early Buddhism tended to deny the possibility of disembodied consciousness between death and rebirth, the Buddhist tradition soon developed the idea of just such an intermediate state after death, called antarabhava in Sanskrit. This statc was little discussed, but it accounted for the personal and psychic continuity needed between a person's death and the rebirth of that person's consciousness in another body. Since Vajrayana Buddhism had already rehabilitated the soul, alias the alaya-vijnana, which was thought to continue from one body to another, it was natural that it should also welcome the concept of an intermediate state between incarnations. The Tibetans called this state the bardo.

The sutra called the Bardo Thodol (or thosgroll) is a text for "salvation by Hearing while in the Intermediate State" (Hoffman, 1975 , p. 162). It is read to the dying or dead person to explain to the soul the various phenomena it will encounter and to encourage it to a desirable rebirth. The text of the Bardo Thodol, or Book of the Dead, as it is commonly translated, purports to date back to the founder of Tibetan Buddhism, Padma Sambhava himself. There is no doubt that the teachings therein are of great age, for both the imagery and philosophy show many traces of Bon influence. How- 
ever, the first known use of the Book dates to the eleventh century, when it was "miraculously discovered" among the many "treasure writings" (gTermas) that the lamas claimed Padma Sambhava had buried for posterity (Hoffman, 1961, p. 64). Some of these treasure writings were obviously fakes designed to lend an aura of authenticity to the old Nying-ma-pa school, in the face of Buddhist reform and innovation in the eleventh century.

Doubts of its authorship notwithstanding, the Book of the Dead gained wide acceptance among all the major Tibetan Buddhist sects, in very similar versions, showing its inherent compatibility with the Tibetan world-view. Lama Govinda's statement is representative of the general view of Tibetans:

The descriptions of those visions which, according to the Bardo Thodol, appear in the intermediate state (bardo) following death are neither primitive folklore nor theological speculations. They are not concerned with the appearances of supernatural beings, like gods, spirits, or genii, but with the visible projections or reflexes of inner processes, experiences, and states of mind, produced in the creative phase of meditation. ... The Bardo Thodol is first of all a book of the living, to prepare them not only for the dangers of death, but to give them an opportunity to make use of the great possibilities which offer themselves in the moment of relinquishing the body. (Govinda, 1960, pp. 122-123)

In short, the sacred text was thought to have been verified by the meditations of yogins in this lifetime, and it held out the invitation to test its truth by similar practices of meditation. Thus it served simultaneously as a description of what dying people and yogins in death-like trances have experienced, and also as a guide on how to deal with such experiences in one's own meditations and finally in death.

\section{Traditional Deathbed Practices}

The mind or soul (Tibetan: sems) is held to linger around its corpse for several days after the cessation of breathing. While unable to speak, it can see and hear all that goes on. So the Book of the Dead is read in the home in the presence of the corpse (and soul) to protect and encourage it. Even when the soul goes through terrifying or surrealistic visual experiences, it is said that it can still hear the Book being read, echoing like a soundtrack behind the otherworldly visual imagery that it experiences.

In fact, actual practices at death are not so simple or unified. It is not unusual to find several services conducted at once: a Bon 
service chasing evil spirits out of the house and convincing the spirit of the dead person that it is indeed dead and must leave; a Pure Land service invoking Amida to come to the deathbed and escort the soul of the believer to heaven (see Becker, 1981); and a Bardo service occupying one or several weeks, in which the Book is read to guard and guide the soul through its immediate postmortem adventures (Waddell, 1934, pp. 789-793). These practices are not as contradictory as they might seem, for the Bardo allows each soul its choice from among these options: to become a ghost, to be reborn in the Pure Land, or to transcend everything. These variations depend upon the spiritual advancement of the deceased: the average person experiences a loss of consciousness before waking in the Bardo statc; gods and gurus may come to greet the especially pious person at the deathbed, and trained yogins will pass directly into higher states with no loss of consciousness (Evans-Wentz, 1935, pp. 234-236).

The moments immediately surrounding death are sometimes said to be accompanied by a tremendous roaring and crashing sound, by flashes of light and periods of darkness. Commentators consider these to be the physiological side effects of the dissociation of the consciousness from the body, a physically but not spiritually important phenomenon (Evans-Wentz, 1935, pp. 237-243). The location from which the sems, or semimaterial consciousness, leaves the corpse is considered highly important. There are said to be nine places from which the soul may leave the body, but it will fall into subhuman wombs unless it leaves by the parietal aperture (at the top of the skull). This is the rationale given for not allowing anyone to touch the corpse except for the priests, who try to coax out the soul by pulling some hairs from the top of the head (Waddell, 1934, pp. 488-489).

The departure of the soul at death is thought to be identical to the departure of the soul discussed in the literature of OBEs and "astral projection," feats commonly attributed to accomplished yogins (Evans-Wentz, 1935, p. 170). When the consciousness is transferred out of the body, in a process called pho-wa in Tibetan, it is thought to be able to travel freely over distances, or to take up the dead body of some other creature. Meditative pho-wa, or "soul travel," is considered very dangerous; it is only to be undertaken by the adept under the careful guidance of a guru, while someone else remains to protect the original body (Hoffman, 1975, p. 153).

The important point is that in both yoga and Buddhism, the processes involved in meditative travel and in death are essentially alike. The only major difference between the yogic trance and death 
is that in trance, the soul returns to its body after its sojourns, while in death it cannot do so.

\section{The Three Stages of the Bardo}

According to the Book of the Dead, there are three stages to the Bardo, or intermediate disembodied state following death. Each of these stages corresponds to an opportunity to enter a different level of existence in an ontologically different form, viz.: dharmakaya, sambhogakaya, and nirmanakaya (Evans-Wentz, 1935, p. 232).

The first stage is called the Chikhai Bardo. There,

At the moment of death, the empiric consciousness, or consciousness of objects, is lost. This is what is popularly called a "swoon," which is however the corollary of super-consciousness itself, or of the Clear Light of the Void. . . . This empiric consciousness disappears, unveiling Pure Consciousness, which is ever ready to be "discovered" by those who have the will to seek and the power to find it. That clear, colourless Light is a sense-symbol of the formless Void. . . consciousness freed of all limitation. . . Nirvana. (Woodroffe, 1957, pp. Ixxi-lxxiv.)

These visions of pure light may be accompanied by "such a dazzlement as is produced by an infinitely vibrant landscape in the Springtide" (Woodroffe, 1957, p. 1xxiii). Or it may remind one of transparent moonlight, sometimes mistaken for heaven; but it is most often analogized to a blindingly open clear sky (Evans-Wentz, 1935, p. 236, Evans-Wentz, 1957, p. 91). The dying consciousness is advised to identify itself with this light and abandon all traces of self-identification or self-consciousness. Some observers take the halo around a dying saint to be evidence of such identification with the absolute Truth and Light. For the enlightened saint or yogin, this is the consummation of existence: personal consciousness is transcended, temporality is no more, and there is only the unqualifiable Suchness of Nirvana. Lesser yogins or blessed people may be able to retain this vision of the light for several days, but they are eventually pulled away from it by their desires and deluded habits of thinking. For still others, this experience may be no more than a brief flash or glimpse of light (Woodroffe, 1957.) Bound by their karmic cravings and habits of believing in illusions, they regress downward to other levels.

In the second stage, called the Chonyid Bardo, the consciousness clothes itself with a psychically projected body resembling the physical body it had once projected on this material plane. Over the 
course of seven days, seven benign Buddhas appear to the consciousness (the pentad mentioned above, then the Buddha representing the combined deities of the six material realms, and finally the Buddha representing "wisdom holding deities"). Each of these Buddhas is symbolized as a blinding colored light, and with imagery like that of the Tibetan tanka paintings. Again, the soul is urged to identify with these lights, for these are seven last chances to bring itself into spiritual oneness with these Buddhas. If successful, it may dwell indefinitely on their higher planes as a bodhisattva, with no need for further rebirth, and with ideal conditions for progress towards final nirvana. On the other hand, if at any point it is repelled by these visions (because of its recognition of its own impurities), or is more attracted to the dull lights of the lower sensual realms in the opposite direction, it will be reborn into one of the six realms of worldly existence. There is some disagreement among the various sects as to exactly what the order of appearance and the colors of the seven Buddhas are, but this question is of little importance to our study now (Govinda, 1960, pp. 249-252).

If the dead person's consciousness has passed through these seven days of Buddha-manifestations and has neither been able to identify with any of their luminosities nor has fled to any lower realm, then it is confronted with another seven periods in which terrifying deities appear. The Book encourages the soul to see these gruesome apparitions also as mere projections of its own subconsciousness, and to embrace and absorb them without fear, rather than accepting their appearance as reality and fleeing from them. Catholic interpreter Tucci explained:

The forces thus represented are present in all of us, and go to make up our personality of which they form the underlying pattern; they are therefore also the means of salvation, when our gnosis, on understanding their nature, absorbs them. This is the knowledge that annihilates, bringing us back from the apparent to the real, a return to our origin. . . When recognition is absent, such visions would be regarded as the god of death, and death would be believed to be a reality, and the dead man caught up in the succeeding phases of the karmic process. (Tucci, 1967, p. 89)

These terrifying apparitions must not be thought of as the evil counterparts of the previous "good" Buddhas, for in Vajrayana Buddhism, there is neither good nor evil. In fact, both the Buddhas and these Herukas, or lords of death, are no more than the projections of the subconscious mind of the deceased. One can attain spiritual rebirth by knowing that all is spirit, by identifying with 
these brilliant or terrifying images and granting neither them nor oneself any objective reality. If the consciousness has still been unable to yogically identify itself with any of these apparitions during the first two weeks after death, it then proceeds still further into a period of prematerial existence.

The third period, called the Sidpa Bardo, depicts the consciousness clad in a body of subtle matter. Conscious of the material world (and its six realms), the soul has the powers of astral projection, such as moving at will through objects and across distances instantaneously. The consciousness first perceives its old home and family in mourning, and tries to convince them that it has not died, but to no avail (Evans-Wentz, 1957, pp. 160-166). Unable to reenter its cremated or dismembered corpse, blown by the "winds" of karma, it wanders forth feeling homeless and miserably alone, realizing for the first time that it is dead to other humans. It may try to rest in graveyards or temples, but as its nature is pure consciousness, which it has not yet learned how to calm or control, it may not rest for long in any one spot. The Book predicts visions of fearful precipices and chasms and feelings of being crushed or squeezed into crevices.

Finally, the soul perceives the lord of death and his demons come to judge it (Hoffman, 1975, p. 162). It sees its good and evil deeds weighed before it, and feels itself hacked and racked by demons. Since its new body is a mental projection, it is not destroyed, but continues to feel these (self-) punishments as long as the reality of that body and its sins are adhered to. Finally it is released, only to be pursued by furies across many strange landscapes prior to material rebirth.

At any point in this last process of the Sidpa Bardo-whether as a disembodied soul, as a judged and tortured being, or as a spirit pursued by furies-it may yet escape. It may transcend the whole illusion of misery and suffering by fixing its mind on Amida, Kwanyin, or any other patron bodhisattva. If it can hold such imagery in its mind, it can cast out all other self-created imagery of fearful visions, and it may yet rise to the Pure Land or Tusita heavens to meditate in the company of the saints and avoid further rebirth. However, it is much harder to hold an image of Amida in mind while one imagines oneself being tortured, than when that image presents itself vividly and naturally in the Chonyid Bardo stage. Therefore not many are able to reach transcendence at the Sidpa stage, although the Book is read as a spur in that direction. 
The more average consciousness, after a seemingly endless period of tortures (which actually take place in a few weeks of human time), again finds itself looking at the six material realms, now chastised in spirit. Premonitory scenes of different landscapes indicate the type of body into which its consciousness will be reborn. Seeing beautiful bodies in the sex act, it is drawn towards its old pastime, and finds itself drawn into a womb of its own choosing. Some interpreters say that it may be drawn into animal or divine wombs depending on its flight from the furies; others, that all rebirth at this point is on human level (Evans-Wentz, 1957, pp. 180-185). The Book urges the consciousness (if it is still listening at all!) not to choose by physical attraction, but to choose a home with parents of pious character and adequate wealth to permit their offspring to follow the yogic religious path and progress yet higher in the next round of existence (Evans-Wentz, 1935, p. 246).

\section{The Death of Great Souls}

The saints and yogins go directly to nirvana or become bodhisattvas in the higher heavens at their deaths. The "great incarnation" lamas-the spiritual and secular heads of the great lamaseries and districts of Tibet-are said to have a somewhat different mode of progress. The Dalai (political head) and Panchen (spiritual head) lamas are thought to be the material manifestations of the bodhisattvas Kwan-yin and Amida, respectively. Accordingly, they undergo no illusory visions during the 49-day period during which average souls are said to wander through the three Bardos. Before their deaths, they indicate the region of the country and the characteristics of the family into which they plan to be reborn. After they die, families expecting babies in those regions are sought out. Babies showing miraculous signs 49 days after the lama's passing are inspected for birthmarks and other similarities to the departed lama (Hoffman, 1975, p. 167). They are then placed in a room with a number of sacred objects, some of which had belonged to the previous lama (Ellam, 1927, pp. 42-43). The baby who shows the most marked preference for those objects alone is then singled out for special attention. The priests put the child to further tests of identity, while conducting divination and prayer ceremonies, and the country or diocese is temporarily ruled by regents. The body of the departed predecessor is carefully preserved in a chorten (stupa).

At the age of four, the chosen child assumes the garb and tonsure 
of a monk; at eight, he is made abbot of a convent; and at eighteen, he is installed with the full powers of the highest lama (Waddell, 1934, pp. 229-253). Thus, there is a sense in which the highest lamas are never discarnate from the world for more than 49 days. This is only possible because the bodhisattvas Amida and Kwan-yin are miraculously able to maintain both a nirmanakaya (fleshly body) in this world and a sambhogakaya (spiritual body) in their respective Buddha-ksetra (heavens) simultaneously.

Although this practice of reincarnation lamas dates back only about 500 years, it is sometimes accompanied by such miraculous occurrences that even critical Western observers have been impressed (David-Neel, 1931, pp. 122ff). While there are elaborate ceremonies surrounding the deaths of incarnate lamas, there is no need for others to read to them from the Book of the Dead, since they already know the idealistic landscapes to come and how to deal with them (Waddell, 1934, p. 494).

The Book of the Dead, then, is not a Dantean description of eternal heavens and hells. Rather, it is a chronological review of the gateways to numerous postmortem levels of experience during the intermediate state between incarnations, usually 28 to 49 days. Its imagery incorporates all of the possible afterlives that Buddhists have yet envisioned: total transcendence into nirvana; ascension to heavenly Pure Lands; life-review, judgment, and torture; disembodied existence as an invisible ghost; rebirth in this or other worlds. Its reconciliation of so many traditions is based, not on crude eclecticism alone, but on a profound philosophy of absolute idealism, buttressed by a long tradition of experience in yogic meditation (Govinda, 1960, p. 125).

The thrust of Vajrayana philosophy is that all meditative and postmortem visions are mentally projected images. (We may recall H. H. Price's [1953] discussions of postmortem image-worlds and the inabilities of dead people to believe that they had died-paralleled by the experiences predicted in the Book of the Dead.) This does not mean that imaginary experiences are less important, however, because the experiences of this present world are held to be equally illusory from an enlightened perspective! (Evans-Wentz, 1935, p. 167)

Vajrayana Buddhists say that any explanation of reality based on the physical senses or on the appearances of the material world is ultimately doomed to failure. Although there is some measure of shared illusion (intersubjectivity) on each level, the laws and structures of any given realm may be violated at will by one who has yogically perfected his mind and come to know their unreality. The 
Tibetans can also explain their siddhas, or miracle-working lamas and yogins, on this model. This philosophy allows students of the Book of the Dead to predict that the heavens, judgments, or ghostly scenarios described by other religions may have equal claims to (provisional) validity.

\section{Theoretical Implications for NDEs}

The Tibetan Book of the Dead, while based on centuries of meditation and deathbed experiences, cannot be proven true or false at this point. However, if it were accepted as providing a widely applicable description of afterdeath experiences, it would explain some otherwise inexplicable observations made of near-death experiencers in America. Let us dare to speculate about a few of these possibilities:

First, the majority of near-death experiencers in the West report either OBEs, passing through darkness to meet a figure of light, heavenly scenery, or some combination of these. While some fundamentalist researchers have sought reports of hellish visions as well (Rawlings, 1978), the preponderance of reports are of beatific visions. According to the Book of the Dead, this may be due not to the benevolence of God nor to the absence of Hell, but to the order of postmortem experiences. In other words, heavenly visions occur in the first week after death, and hellish visions in the second. Indeed, this temporal sequence is taken very literally in Tibet, where the proper chapters are read into the ear of the corpse on the proper days after death, so that the soul, if it is listening, may be more wisely guided through the experiences that await it, and may choose a better rebirth, or none at all.

Since all of our resuscitated NDE reporters in America have been dead far less than a week, the Book of the Dead would lead us to predict that they should have beatific rather than hellish visions, which is in fact what they report. Now it may well be argued that the terms "week" or "second week" are not exact measurements; that people may pass through these stages at different rates, and therefore that some may experience hellish visions even if dead only briefly. But since the order of visions is from heavenly to hellish (which may in turn be followed by heavenly saviours or premonitions of reincarnation), it would stand to reason that more of those who revived would report the former than the latter. If the Book of the Dead is correct, some of those who remain dead are also passing through hellish visions (although they cannot report them to us) 
unless they have already transcended to a higher existence.

Secondly, Ring (1980, p. 136) reported the surprising and inexplicable finding that those with prior knowledge of NDEs were less likely to experience them, and those with no prior knowledge were more likely to do so. The Tibetan tradition gives us some ways of approaching this problem as well. First it says that all such visions are mental projections of the percipient. It also holds that those who know what the postmortem experience is like (such as lamas) can thereby avoid the series of delusionary experiences that normal people undergo. By similar logic, those who have no knowledge about NDEs simply and naively project their own mental imagery onto the screen of their experience, and report such NDEs when they revive. Knowing nothing in advance about this phenomenon, expecting nothing, their consciousnesses simply manifest naturally their inner imagery, as we do when we dream. However, those with prior knowledge of NDEs may to some degree expect the NDE to happen to them, as if given from some external source. Since NDE visions are not given from some external source, but projected from within (if we accept the explanation of the Book of the Dead), then many of them await such experiences without generating or projecting anything on their own; and the result is that they experience nothing. If NDE visions are objective observations of another world, it is hard to explain why those with prior knowledge of NDEs have fewer such visions. If NDE visions are projections of personal imagination, then those without prior knowledge will allow their imaginations to run freely, hence experiencing prototypical NDEs. Those who expect the NDE to be given to them "from the outside" and simply wait for it to happen, however, will find that nothing occurs at all in their waiting minds-and they fail to report typical NDE visions.

Thirdly, the theory of the Book of the Dead that all such visions are projections of consciousness would help to explain the wide variation in details of visions among different persons and cultures, and would suggest that cultural conditioning may play some part in the content of NDEs. Of course, further data collection and analysis are essential before we can say how similar or different are visions from cultures with drastically different religious educations and expectations. Osis and Haraldsson found some differences between contents of Indian and American visions (1977), but even their study tended to focus on Indian Christians rather than Hindus and Buddhists. It would be most informative to collect such data from persons with Hindu, Buddhist, or other drastically 
non-Western world-views. If indeed there are major differences in the visions of such cultures, then we might well conclude, not that the same reality is being differently labeled by different people, but that the perceived reality is in fact a projection of the minds of people in these different cultures.

To call these visions mental projections, however, is not to question their reality at all. Rather, it is to indicate that they are subject to psychic rather than physical laws and regularities. There still seem to be regularities within these experiences, and the fact that they are psychically caused (if so) does not deny the fact that they are experienced as very real. But it changes the philosophically central question from: "What is the landscape of the next world like," to "What causes or conditions the regularities in our minds such that our postmortem experiences come out to be seen as they are?" If the next world (or even this world?!) is structured by mind, and not matter alone, we still have much to learn about the ways in which our minds create and structure experience, and this becomes an exciting and important field to explore as well. We still want to know "How is the next world structured?" But we should expect the answer not in some otherworldly geophysics, but rather in a deeper investigation of the life of the mind, into how mental experiences are structured, and by whiat.

This conclusion is far from a pessimistic one. To say that afterlife experiences are mental projections does not deprive them of reality. Rather, it emphasizes that what is important hereafter is the continuing life of the mind. If in fact the afterlife is some other physically conditioned universe that we cannot sense while in our present bodies, then it is impossible to investigate it at all, except from the reports of those who have touched its fringes in NDEs and returned to tell the tale. If, however, afterlife is composed of mental imagery, there are many ways we can approach its investigation here in this world, by studying the mental and psychic states of many persons, and seeing how those states influence their NDEs. Regardless of which hypothesis is correct, the Tibetan Buddhist tradition lends further support to the idea that NDEs happen in widely disparate cultures and periods of history. We should be encouraged to seek further interrelationships among NDEs, the circumstances surrounding death, and human consciousness. 


\section{REFERENCES}

Becker, C. B. The centrality of near-death experiences in Chinese Pure Land Buddhism. Anabiosis, 1981, 1, 154-171.

David-Neel, A. Heilige und Hexer. Leipzig: F. A. Brockhaus, 1931. Ekvall, R. K. Religious Observances in Tibet. Chicago: University of Chicago Press, 1961.

Ellam, J. E. The Religion of Tibet. New York: E. P. Dutton \& Co., 1927.

Evans-Wentz, W. Y. Tibetan Yoga and Secret Doctrines. London: Oxford University Press, 1935.

Evans-Wentz, W. Y. (Ed.). Tibetan Book of the Dead (Kazi Dawa Samdup, Trans.). London: Oxford University Press, 1957.

Govinda, A. Foundations of Tibetan Mysticism. New York: E. P. Dutton \& Co., 1960.

Hoffman, H. The Religions of Tibet. London: George Allen \& Unwin, 1961.

Hoffman, H. Tibet: A Handbook. Bloomington, IN: Indiana University Research Center for the Language Sciences, 1975.

Nencsky-Wojkowitz, R. Oracles and Demons of Tibet. The Hague: Mouton, 1956.

Price, H. H. Survival and the idea of another world. Proceedings of the Society for Psychical Research, 1953, 50, 1-25.

Osis, K., and Haraldsson, E. At the Hour of Death. New York: Avon, 1977.

Rawlings, M. Beyond Death's Door. Nashville, TN: Thomas Nelson, 1978.

Ring, K. Life at Death. New York: Coward, McCann \& Geoghegan, 1980.

Tucci, G. Tibet, Land of Snows (J. E. S. Driver, Trans.). New York: Stein \& Day, 1967.

Waddell, L. A. The Buddhism of Tibet, or Lamaism. Cambridge: W. Heffer, 1934.

Woodroffe, J. The science of death. Foreword to W. Y. Evans-Wentz (Ed.), Tibetan Book of the Dead (Kazi Dawa-Samdup, Trans.). London: Oxford University Press, 1957. 
Requests for reprints to:

Carl B. Becker

Tenri University

Anglo-American Studies Department

Tenri-shi, NARA 632

Japan 